АРОНСОН О. (2017). СИЛЫ ЛОЖНОГО: ОПЫТЫ НЕПОЛИТИЧЕСКОЙ ДЕМОКРАТИИ. М.: ФАЛАНСТЕР. 446 C. ISBN 978-999999-0-42-4

\author{
Александра Володина \\ Аспирант Института философии Российской академии наук \\ Адрес: ул. Гончарная, д. 12, стр. 1, г. Москва, Российская Федерация 109240 \\ E-mail: sasha.volodina@gmail.com
}

На протяжении всей истории философии язык философского рассуждения и письма постоянно трансформировался, реагируя на общественные изменения. Новые проблемные точки требовали нового понятийного аппарата и новых стратегий описания, и философия современности занята решением этих же задач. Однако сегодня нам кажется интересным не просто прослеживать хронологию процесса изобретения и переизобретения языка мышления, но и обращать внимание на изменения механики самого процесса. Новизна того или иного подхода может состоять не только в экспериментах с лексикой и синтаксисом философии, но и в поиске разнообразия условий для потенциальных изменений. Механика открытия нового может основываться как на обновлении уже существующей традиции, так и на попытках её деконструирования, а также на радикальной смене оптики - то есть отказе работать в рамках существующих теоретических структур, где значения и употребление самих терминов «традиция», «система», «понятие», «теория» и др. чётко закреплены. Эксперименты с переосмыслением не методологий, но условий возникновения и функционирования методологий, а также внимание к потенциальным возможностям мышления, лежащим за их пределами, в иной координатной сетке, могут оказаться весьма продуктивными для исследования современной культуры, в которой в свою очередь происходят те же процессы - не только и не столько обновления, сколько трансформации системы координат. Вслед за Ж. Делёзом и Ф. Гваттари мы можем рассматривать философию не только в качестве «искусства формировать, изобретать или же изготавливать концепты». Отказываясь использовать механизмы, производящие универсалии, и предлагая расширенное понимание концепта (который не обязательно является универсалией, находкой или продуктом), Делёз и Гваттари называют философию «дисциплиной, состоящей в творчестве концептов» (курсив авторов) ${ }^{1}$. Меняющийся мир и новые формы жизни и культуры требуют изменений не только языка описания (точнее, языков - во множественном числе), но и представлений о языке и о мышлении, а также представлений о том, кто же сегодня пользуется этим языком, как и где сегодня возникают новые смыслы и как возможно с ними рабо-

\footnotetext{
() Володина А. В., 2018

() Центр фундаментальной социологии, 2018

DOI: $10.17323 / 1728-192 X-2018-3-389-399$

1. Делёз Ж., Гваттари Ф. (1998). Что такое философия? / Пер. с франц. С. Н. Зенкина. СПб.: Алетейя. С. 14.
} 
тать. С этим кругом вопросов и связана книга философа и теоретика кино Олега Аронсона.

Тексты, составившие сборник, не объединены общей темой или методологией, поскольку каждый из них глубоко контекстуален и вырастает из локальной культурной ситуации. Именно конкретная, локальная проблемная точка, а не абстрактная теоретическая проблема, становится отправной для выстраивания как логики рассуждения, так и понятийного аппарата. Подобное смещение акцентов, безусловно, так или иначе, характерно для многих направлений современной философской мысли - от спекулятивной философии и объектно-ориентированной онтологии до феминистской философии. В этом году книге «Силы ложного» была присуждена Литературная премия имени Александра Пятигорского, вручаемая за лучшее философическое сочинение на русском языке. Председатель жюри премии Ксения Голубович также упомянула об этой смене вектора размышления, отметив книгу «за современность философского подхода к описанию актуальной действительности, за разработку русского философского языка в свете вызовов большого мира, на равных условиях со всеми, без скидок на национальные особенности» ${ }^{2}$. Сам автор в предисловии указывает, что объектами его исследований являются те связи и отношения, которые выступают свидетельствами радикальных перемен, происходящих в современной жизни. Чтобы уловить потенциал нового смысла, изменяющего или подрывающего структуру, в которую уже, казалось бы, встроена та или иная культурная ситуация, нужно предпринять попытку рассуждения на языке, имманентном этой ситуации. А поскольку сегодня производство отношений и смыслов «куда в большей степени обусловлено нашей принадлежностью общности, нежели ценностью индивидуального» (с. 12), что стало следствием развития массового общества и новых технологий, то Аронсона главным образом интересует общность, её логика и практики. Чтобы понять нечто об общности, нужно создать новый способ разговора о ней.

Вектор интерпретации понятия общности, пожалуй, центрального в этой книге, во многом близок теории множества (multitude) П. Вирно, М. Хардта и А. Негри, которые в свою очередь опираются на рассуждения Спинозы о массе и толпе (Аронсон подробно рассуждает о разных подходах к политическому потенциалу толпы у Спинозы и Гоббса в тексте «Эпидемиология политического»). Как пишет Вирно, в отличие от гоббсовского «народа», обладающего единой волей и способного на единое действие ${ }^{3}$, miltitudo Спинозы - это «множественность, которая существует как таковая на общественной сцене, в коллективном действии, по отношению к общим делам, не соединяясь в Едином и не растворяясь в центростремительном движении» ${ }^{4}$. Сам же Вирно развивает понятие множества,

2. Речь председателя жюри Литературной премии имени Александра Пятигорского. См.: http:// piatigorskyprize.ru/news/124.

3. Гоббс Т. (1989). О гражданине / Пер. с лат. Н. А. Федорова // Гоббс Т. Сочинения. Т. 1. М.: Мысль. C. 395 .

4. Вирно П. (2013). Грамматика множества: к анализу форм современной жизни / Пер. с ит. А. Петровой под ред. А. Пензина. М.: Ад Маргинем. С. 10. 
демонстрируя, что в современную эпоху множества получают возможность существовать благодаря general intellect - «общему интеллекту», «общим местам» лингвистических, культурных и логических конструкций, обеспечивающих связи и отношения, и именно эти отношения (а не совокупность индивидов) и представляют собой множество. Таким образом понятое множество, или общность, обладает собственной логикой действия, и эту логику Аронсон называет аффективной. Понятие аффекта, следуя делёзовскому подходу, нам следует отделять от понятия эмоции, связанной с психической жизнью индивида. Область связей, порождённых аффектом, это «особая чувственность общности» (с. 57), которая всегда процессуальна - аффективное событие подразумевает выход за пределы индивидуального переживания и движение к не-человеческому, становление множеством - то есть чем-то совершенно иным, нежели единичной личностью.

Как свидетельствует эта книга, исследования общности, специфики коллективной чувственности и коллективного действия могут проводиться на самом разнообразном материале. Именно живая конкретность материала, исходя из которой выстраивается рассуждение, позволяет по-новому ставить проблемы и открывать новые способы уловить характер той общности, которая не только не оформилась в единое, аналитически схватываемое целое, но и принципиально недоступна для схватывания, незавершимая и нередуцируемая до единичности. Говоря о такой общности, Аронсон описывает её как «грядущую» - как то чувственное событие, которое уже затрагивает нас, но пока ещё не поймано в сетку культурных структур, систем и институций, поэтики и политики. Подобное сообщество грядущего, «множественность отношений существования определяет мир до его схваченности тем или иным способом ввести заново единство бытия» (с. 43). Чем же являются эти метки грядущего, свидетельства перемен, происходящих прямо сейчас? Это указатели на места неразличимости, события, переживаемые ещё не оформленной общностью, ускользающие от существующих структур и бинарных альтернатив и открывающие новые практики и формы чувствования. Поскольку речь идёт о чувственных формах, в книге много внимания уделяется искусству. Однако аффективная логика коллективного чувствования призывает к тому, чтобы отказаться от традиционного эстетического инструментария и попытаться прочесть культурные тексты под новым углом. Аронсон пишет о литературе - «Крейцеровой сонате» Л. Толстого (статья «Искусство и половой хиазм») и «Дракуле» Б. Стокера («Трансцендентальный вампиризм»); о кино - «Шоа» К. Ланцмана («К антропологии свидетельства») и «Советнике» Р. Скотта («Снафф: популярная механика»); o readymade М. Дюшана («Машина и женщина (неискусство Марселя Дюшана)») и акционизме П. Павленского («Право на искусство»). В тексте о поэзии Мандельштама («Товарищество земли (логика стихий Осипа Мандельштама)») находим объяснение того, почему материал искусства оказывается так важен для разговора об общности. Отходя от привычного литературоведческого анализа поэзии, прочитывающего образы как «поэтические, риторические тропы или смысловые конструкции» (с. 57), и принимая, что стихотворение необязатель- 
но должно рассматриваться как завершённая форма и может включать в себя различные, в том числе и несовместимые вариации, можно расширить понимание образа, включив в рассмотрение отношение образов, речевых фигур и сил между собой и эффекты, порождаемые этими отношениями. В привычном восприятии стихотворения «чувственность общности, данная в отношении образов между собой, стирается», в то время как у Мандельштама аффективный план стихотворения является и темой, и задачей, и способом её решения. В «Стихах о неизвестном солдате» способ выражения общности раскрывается через фигуру «неизвестного солдата», «в которой соединено единичное индивидуальное существование (сингулярность) и анонимность множества в его исчезновении, в коллективной гибели» (с. 55). Потенциал расширительного понимания образа не ограничивается только эстетической сферой - а точнее, показывает (что становится очевидным во многих текстах этого сборника), что изолировать реальность эстетического от повседневной действительности вообще едва ли продуктивно. Образы, скрепляющие «собой практику сосуществования людей друг с другом», Аронсон и называет «силами ложного», которые «выявляют отношения, для которых логика противопоставления истины и лжи уже не работает» (с. 9).

Проблематизация бинарных оппозиций - один из основных векторов этой книги. Противопоставления истины и лжи, мужского и женского, силы и слабости - привычные культурные структуры, однако эффекты коллективной чувственности не встраиваются в эти оппозиции. Они не только избегают их, но и проблематизируют, ставят под вопрос. Именно эти ситуации подрыва бинарных структур интересны исследователю, поскольку действительно способны открыть доступ к иным альтернативам и новым смыслам. Таким подрывным механизмом может, к примеру, стать описанная Львом Толстым логика «заражения» искусством, неполитическая общность киевского Майдана и неполитическая солидарность, «грубый коммунизм» или «грядущий» феминизм. Во всех этих кейсах схватываемые философом «силы ложного» действуют парадоксальным образом - они обладают как потенциальной подрывной силой, так и слабостью, которая в свою очередь тоже обнаруживает подрывной потенциал. Эти образы-силы не наделены властью и, более того, открывают пути для ускользания от властных структур; они занимают слабую позицию, вне мейнстрима и где-то на границах ценностных иерархий, основываясь не на присвоении, но на даре. Эти силы жизни «всегда слабее сил политики» (с. 122), и порождаемые ими различные стратегии избегания власти, с одной стороны, отчасти лежат в области несбыточного, принципиально незавершимого, а с другой - именно они и маркируют способы выхода из ловушек бинарных оппозиций.

Подзаголовок книги «Опыты неполитической демократии» подчёркивает ещё одну важную проблемную линию, тесно связанную со спецификой бытия общности. Многие тексты в «Силах ложного» так или иначе затрагивают тему политики и власти. В современном западном мире капитализма, где демократия является признанной ценностью, политика как устоявшаяся система властных отношений, 
с одной стороны, обросла неразрешимыми противоречиями и апориями и имеет ряд ограничений, которые в рамках собственных системных механизмов кажутся непреодолимыми, а с другой стороны, обладает мощной апроприирующей силой, распространяясь на все доступные общественные, культурные и знаковые территории, институциализируя их и включая в структуру властных отношений. Возможно ли в сегодняшнем мире существование нескомпрометированных зон неполитического, ускользающих от апроприации и представляющих альтернативный, продуктивный взгляд на апории политического? Эта книга посвящена зонам, где неполитическое измерение общности обнаруживает себя и где действуют «слабые силы», создающие эти общности свободы. Важно отметить, что такие общности легче именно обнаружить, а не помыслить - об этом, в частности, читаем в тексте «Анархическая этничность», где автор рассуждает о возможности неполитической этничности. Общность-множество непредставима, поскольку логика её возникновения противоречит самому механизму представления: если политическая этничность, стремящаяся к тому, чтобы объединиться в государство, формируется благодаря инструментарию идентификации по принципу «свой - чужой» и, следовательно, сама формирует чёткое представление о себе как о единстве, то анархическая этничность действует через ускользание и исход, через отступание от стратегии идентификации индивида как части единства. Понятие «исход» в данном случае не метафорично, а конкретно - рассуждения автора разворачиваются на материале еврейской мифологии, где реализуются обе линии формирования этничности; первая из них, политическая линия, действует благодаря фигуре героя и пророка Моисея, а вторая логичным образом не эксплицируется из какоголибо конкретного индивидуального воплощения, поскольку логика её развития в нём не нуждается. Общность в исходе не стремится к объединению в действии, но возникает благодаря и во время этого действия - иначе говоря, составляющие её отношения внутри множества складываются вынужденно, «в слабости», в побеге. Это общность с теми, с кем мы не способны её представить; с теми, с кем ты обречён на совместное выживание. Оптику, позволяющую усмотреть эту общность, мы можем обнаружить в мифологии, тем самым попытавшись, во-первых, приблизиться к пониманию строения общества до государственности, а вовторых, увидеть действие мифологической этики в современном мире - этики, избегающей политического. Отказ от идентичности, от «противопоставлений «друг - враг», «свой - чужой» как оснований некоторой поведенческой этики» (c. 130) - это слабая позиция в рамках господствующей общественной системы и экономики, однако она оказывается чрезвычайно гибкой и жизнеспособной, функционируя в рамках другой экономики - экономики не обладания, но дара. Опираясь на труды антропологов и философов, писавших о логике дара, Аронсон подходит к разговору об этике гостеприимства. В дерридианской трактовке понятие «событие гостеприимства» обнаруживает возможность обойти не только дихотомию «свой - чужой», окрашенную негативным отношением к «чужому», но и «свой - другой», в логике которой даже позитивная открытость другому вле- 
чёт за собой вписывание его в жёсткую рамку оппозиции, несущую в себе «вирус противостояния» (с чем в современную эпоху западное общество неоднократно сталкивалось, пытаясь разрешить проблемы колониализма, выйти из ловушки неизбежной экзотизации других культур и справиться с побочными эффектами «политики идентичности», которая подразумевает присвоение ценностей какой-либо группой и необходимость выбрать своё однозначное положение на шкале «свой чужой»). Отказ же от идентичности влечёт за собой потенциал безусловной открытости, готовности быть вовлечённым в аффективное переживание общности.

Механизм этой вовлечённости удачно раскрывается через понятие заражения, потенциал которого Аронсон описывает в тексте «Искусство и экономика бедности (заметки о теории заражения Льва Толстого)». И хотя о механике заражения Толстой писал применительно к искусству (работа «Что такое искусство?»), тем не менее сфера его действия не ограничивается областью эстетического. Следует оговорить, что интерпретацию заражения Аронсон не заимствует у Толстого, но развивает, прочитывая его чуть иначе, чем все мы привыкли, перетолковывая и иначе расставляя акценты. Определяя искусство как коллективное дело, Толстой пытается выявить принципы настоящего искусства и ложного. В качестве определяющего принципа для этого разделения он рассматривает красоту, но обнаруживает несостоятельность этой категории («с ее миметизмом, формой и техникой представления и ее подспудным эротизмом» (с. 288)), что вполне созвучно консенсусу в большинстве направлений мысли современной эстетики. Подлинное искусство, управляемое действием заражения, пишет Толстой, есть «средство общения людей, соединяюеее их в одних и тех же чувствах». Предостерегая против психологической интерпретации этого явления, Аронсон подчёркивает слова Толстого о том, что при заражении «человек с целью передать другим людям испытанное им чувство снова вызывает его в себе и известными внешними знаками выражает его»- то есть механизм заражения переводится из внутреннего, субъективно-психологического пласта вовне, в область коллективных форм жизни. На нас воздействует не авторская интенция или личные переживания автора или исполнителя, но «некая бессубъектная форма произведения» (с. 291), складывающаяся в процессе действия аффективных отношений - не объект или образ, но аффект или сила. Таким образом, механика заражения не встраивается в «наши привычные дихотомии идеальное/материальное, рациональное/чувственное, внутреннее/ внешнее» (с. 294) и осуществляется именно в общности людей, захваченных теми или иными отношениями чувствования.

«Заражённое» сообщество действует в том режиме общности, который «можно назвать коммунизмом без идеологии, или коммунистической чувственностью» (с. 298). Неидеологический и неполитический, «грядущий» коммунизм в «Силах ложного» подробно рассматривается в текстах «Грубый коммунизм, или Этика праздности» и «Искусство и половой хиазм». Понимая под коммунизмом тот тип отношений, в котором «преодолен отчужденный трудом индивид во имя неотчуждаемой общности» (с. 23), Аронсон отталкивается от линии рассуждения 
К. Маркса, называвшего «грубым коммунизмом» реальные коммунистические практики, уже существующие в общности и обладающие критическим потенциалом по отношению к господствующим властным структурам. Это практики такого труда, который не воспринимается как ценность (и, собственно, как труд) самим участвующим в нём сообществом. Специфика таких практик раскрывается как в искусстве и инновациях, так и в весьма провокативных зонах общности: воровстве (не просто нарушающем закон, но меняющем само отношение к собственности) и проституции, трактуемых как поле сопротивления господствующему типу общественных отношений и та область, в которой реализовывается «освобождённый труд» женщины. Хотя следует отметить, что с учётом социокультурных данных о том, как плачевно обстояли и до сих пор обстоят дела в индустрии проституции, авторская аргументация порой представляется дискуссионной (к примеру, тезис о том, что проститутка «не принадлежит мужчине, она не участвует в процессе производства, она не трудится в привычном понимании этого слова. Покупается ее время, но это время ее жизни, а не «рабочее время» пролетария, из которого извлекается прибавочная стоимость» [с. 34]).

Однако проблематика женского в книге встречается в разных контекстах и оказывается указателем на различные области неразличимости, «слепые пятна» власти и политики, границы аффективных общностей. Именно силы и практики женского позволяют высветить возможности ускользания от контроля власти, поскольку они связаны с иными типами труда и зарождаются в «зонах неразумного - в чувственности и в сексуальности». Область женского - «место, где никакое господство невозможно», и по-настоящему подрывной потенциал женского проблематизирует власть мужского, не стремясь при этом занять место мужчин в структурах господства. Таким образом, продолжая линию мысли Толстого в «Крейцеровой сонате», Аронсон рассуждает об отношениях полов не как о конфликте, а как о хиазме, замечая, что в сегодняшнем мире «сам акт именования чего-то как мужского и женского становится опасным и практически невозможным», и предлагая тем не менее попытаться вернуть возможность размышления в этих терминах, поскольку «мужское» и «женское» даны нам «как факт нашей жизни» (с. 324-325). (Последний тезис с точки зрения феминистских и гендерных теорий тоже может показаться дискуссионным, в том числе потому, что в следовании этой логике возникает риск вновь вернуться к исследованию не отношений, а объективированных конструктов.) Однако памятуя об основном проблемном векторе книги - обнаружении тех практик общности, которые дают возможности продуктивной критики бинарных структур и противостояний, - обратим внимание на критический потенциал общности «женского». Эту этику женского, как представляется, следует рассматривать в тесной связке с проблематикой солидарности (о которой Аронсон пишет в других текстах - «Майдан: переопределение демократии» и «Государство непокорности (возвращаясь к Генри Торо)»), смещая акцент с гендерной идентичности и таким образом избегая отмеченных выше спорных решений. «Солидарность» здесь также раскрывается как понятие непо- 
литическое, ускользающее от политической институциализации, - она «ощутима, пока люди объединены не властью и не борьбой за нее, а смутным намерением, общим импульсом, общностью действия» (с. 249), где действие оказывается вне механизмов существующих общественных субститутов солидарности (партий или группировок по интересам), вне правовых механизмов и сферы действия законов. Такое неполитическое действие таким образом необязательно является незаконным - в качестве объектов рассмотрения выбраны движение "Оссиру» (его московская версия у памятника Абаю на Чистых прудах в 2012 г.) и сочинение Генри Торо «О долге гражданского неповиновения», где он пишет об отказе от уплаты налогов и отношениях с представителями закона, и ставит под сомнение саму формулу представительства, которая противостоит прямой солидарности. Именно через конкретное действие неповиновения и «открывается возможность альтернативного взгляда на политику, когда «ущерб», «слабость» и даже «обреченность» каждого отдельного индивида оказываются строительным материалом для той «пассивной революции», достижений которой всегда не замечают и недооценивают, поскольку подчинение одному закону спешно сменяет подчинение закону новому» (с. 250). Справедливо критикуя революционный протест, совершающийся в логике государственности и тем сам влекущий вслед за подрывным процессом возвращение к воспроизводству той же политической логики, что господствовала до переворота, Аронсон вслед за Торо пишет о коллективном действии, основанном не на протесте, а на долге - долге неповиновения и солидарности.

Представляется, что этика «женского» в упомянутой выше трактовке чрезвычайно близка этике солидарности, а также этике заботы. В истории понятие солидарности возникает в различных теоретических контекстах, и даже в отдельно взятой области философии значение этого понятия сохраняет свою неуловимость и вариабельность. Это объясняется тем, что сегодня мы говорим в первую очередь о практиках солидарности, то есть о солидарности как факте жизни, воплощающейся лишь в динамике отношений между людьми. Когда солидарность определяется через коллективную практику ${ }^{5}$, а не в качестве принципа (как, скажем, в логике мысли Э. Дюркгейма, изложенной в работе «О разделении общественного труда»), ценности или чувства ${ }^{6}$, она не рассматривается как неотъемлемое или приобретаемое свойство человеческой общности или индивида и связывается не с объектами, а с их отношениями (следуя этой же логике, философ Матти Хяурю противопоставляет практики солидарности абстрактным ценностям независимости и справедливости ${ }^{7}$. Также намечая линию философской критики представлений о справедливости, Аронсон пишет о «позитивной несправедливости»- отношении, которое позволяет существовать общности с другим. В этом

5. Prainsack B., Buyx A. (2012). Solidarity in Contemporary Bioethics: Towards a New Approach // Bioethics. Vol. 26. № 7. P. 346.

6. См., например: Stjernø S. (2004). Solidarity in Europe: The History of an Idea. Cambridge: Cambridge University Press.

7. Häyry M. (2005). Precaution and Solidarity // Cambridge Quarterly of Healthcare Ethics. Vol. 14. № 2. P. 199. 
рассмотрении реальности другого не как объекта или образа, а как отношения получает развитие идея Э. Левинаса о бесконечности другого, для встречи с которым приходится преодолевать границы самотождественного «я». Эта слабая позиция «я» освобождает место аффективной силе, возникающей в воздействии позитивной, продуктивной несправедливости, где при встрече обоюдный дар слабости и солидарности создаёт новое сообщество. Итак, вынося явление солидарности за идеологические рамки, мы получаем возможность обнаружить в нём неполитическое измерение.

Солидарность выступает одним из важнейших понятий в этике заботы. Это направление этической мысли, получившее начало в работе «In a Different Voice» (1982) специалистки по психологии и феминистской теории Кэрол Гиллиган, стоит на критической позиции по отношению к классической этике и этике дискурса. В частности, подвергается сомнению способность абстрактных метаэтических теорий стать основой для обеспечения интересов «конкретного другого» и заботы о нём. С позиций феминистской критики и кантовская мораль, и этика утилитаризма в силу своей абстрактности не отвечают специфике конкретных человеческих потребностей и, как и контрактуализм, они не дают достаточного инструментария для исследования отношений внутри групп людей, заботящихся друг о друге ${ }^{8}$. Первые теоретики феминизма XVIII-XIX вв. уже проблематизировали распространённое допущение о том, что полноценно развитой личностью можно полагать ту личность, которая в наибольшей степени автономна и независима от других. Отказавшись от этого допущения, они предложили обратить внимание на важность отношений и связей между людьми и принять в качестве теоретической установки положение о том, что чем более конкретным, частным и эмоциональным является знание, тем более точно оно позволяет рассуждать о реальных переживаниях людей в окружающем их мире 9 . В последние десятилетия ряд теоретиков феминизма исследуют конкретные практики общностей, трактуя заботу как эффект актуальных совместных практик, а не как частную эмоцию или универсальную ценность ${ }^{10}$. Этика заботы, осмысляющая женский моральный опыт (в противовес «маскулинной» морали, которая в рамках классической этики подразумевалась как универсальная), призвана стать «теоретическим основанием для критики любых социальных практик, поддерживающих подчинённое положение женщин, и для сопротивления осуществлению этих практик» ${ }^{11}$. Как пишет Кэрол Гиллиган, вместо языка справедливости, устанавливающего права и законы, женская этика способна выработать язык заботы, делающий акцент на отношениях и ответственности.

8. Held V. (2006). The Ethics of Care: Personal, Political, and Global. Oxford University Press. P. 24.

9. Подробнее см.: Tong R. (1993). Feminine and Feminist Ethics. Belmont: Wadsworth.

10. Подробнее см.: Ruddick S. (1989). Maternal Thinking: Toward a Politics of Peace. Boston: Beacon; Tronto J. C. (1993). Moral Boundaries: A Political Argument for an Ethic of Care. L.: Routledge.

11. Артемьева О. В. (200о). Этика заботы: феминистская альтернатива классической философии // Этическая мысль. Вып. 1. М.: ИФ РАН. С. 196. 
Также в рассуждениях об этике заботы придаётся особое значение понятию различия, при этом предлагается вынести различия из рамок релятивистского дискурса и не считать их проблемами, требующими разрешения, а воспринимать в качестве видимых «указателей» отношений, меток, указывающих на изменения состояния человека и общности ${ }^{12}$. Женская этическая стратегия включает в своё поле то, от чего абстрагируется «маскулинная» этика - в том числе благодаря осмыслению проблематики различия и её глубокой контекстуализации она получает возможность не отказываться от релятивизма как непродуктивной и неприемлемой позиции в современном обществе, но переориентировать эту проблематику в область отношений и взаимозависимостей. Таким образом, этика заботы открывает способы работать как с недопустимым, так и внеморальным, а моральные высказывания оказываются вариативными, поскольку рождаются в конкретной материи жизни, конкретном событии, в контексте которого они предстают несомненными $^{13}$. Суждения о справедливости в рамках такой этики основываются не на системе норм и ориентации на принцип равенства, а на допущении множественности ситуативных моральных истин ${ }^{14}$. Так, сама этика заботы представляет собой не протест против «мужской» этики, но попытку выхода за пределы её господства; практики заботы и солидарности - не «антимужские», но отличные от них. Таким образом, если расширить рамки разговора об этике за пределы гендерной идентичности (к чему, в частности, справедливо призывают критики феминизма), то этика солидарности и заботы сама по себе может восприниматься как способ ускользания от дихотомических противостояний, а также позволит найти способы рассуждать о множественности общности и в то же время не терять из виду конкретность жизненных отношений.

Возвращаясь к проблеме поиска выхода из ловушки релятивизма, следует отметить, что в определённом отношении эта книга - весьма успешный ход в игре против критиков современного положения дел в гуманитарных науках, культуре и обществе, которые выступают с широкими обобщениями с традиционалистских позиций. Усиление релятивистских настроений часто указывается в качестве одного из пороков современности, однако, как можно заключить, рассуждая о проблематике постправды, происходящие процессы следуют более сложным механизмам, чем гомогенизирующая релятивизация взглядов. Не только содержание информационных высказываний, общественных мнений и истин, но и сами формы представлений общества об истине и мнении, и их воздействия - всё это возникает в качестве эффектов медиа. С ростом разнообразия и дифференциации медиа множатся и эти формы. Перед нами встаёт задача осмысления и обсуждения явлений и идей, лежащих в поле относительного, ложного, внеморального, вне закона; каким может быть исследовательский инструментарий для работы с этими

12. Gilligan C. (1993). In a Different Voice: Psychological Theory and Women's Development. Cambridge: Harvard University Press. P. xviii.

13. Ruddick S. Op. cit. P. 128.

14. Gilligan C. Op. cit. P. 166. 
явлениями, структурами и смыслами, кроме двух очевидных путей - тривиальная релятивизация или апроприация властной риторикой? Эта книга предлагает нам эксперименты по поиску иных альтернатив, поиску ещё не скомпрометированных политикой и идеологией зон, поиску сообществ, которые не ограничены подобно filter bubbles социальных сетей, а открыты, революционны и непредставимы. В последнем тексте книги Аронсон пишет об этике ложного, развивая идею Ф. Ницше о продуктивной фальсификации - то есть о важности и необходимости для жизненной практики человека тех суждений, которые являются ложными и безосновными (каковыми Ницше полагает априорные синтетические суждения), однако универсально сообщаемыми и общими. Медиа и массовые коммуникации, потенцирующие эту сообщаемость, создают бесконечные серии суждений, в данной механике воспроизводства не являющиеся уже ни вполне истинными, ни строго ложными. В стремлении контролировать производство истины политика постоянно имеет дело «с логикой неуникального, с режимами бессмысленных повторов, с аффективными знаками (шоками)» (с. 441), пытаясь их апроприировать, однако в зоне ещё недоговоренной речи, в зоне до суждений можно обнаружить моменты действия аффективной радости обмана, «невидимые анонимные коммуникативные связи, которые ею (политикой) оказываются уже неконтролируемы» (с. 443). Здесь становится совершенно очевидным, сколь сложно теоретику ухватить в качестве предмета исследования то едва намеченное действие сил, создающих ещё не оформившиеся общности, и вычленить тот подрывной потенциал неподчинения, который ещё не пойман институциональной ловушкой политического. Книга «Силы ложного» свидетельствует о том, что подобные исследования не только сложные, провокативные и актуальные, но и чрезвычайно захватывающие для читателя.

\title{
Book Review: Oleg Aronson, Sily lozhnogo: opyty nepoliticheskoy demokratii [Powers of Falseness: Essays on Non-political Democracy] (Moscow: Falanster, 2017) (in Russian)
}

\author{
Alexandra Volodina \\ Postgraduate Student, Institute of Philosophy of the Russian Academy of Sciences \\ Address: Goncharnaya str., 12/1, Moscow, Russian Federation 109240 \\ E-mail: sasha.volodina@gmail.com
}

